\title{
O BLOGUE NA APRENDIZAGEM DA LINGUAGEM ESCRITA: estudo de caso numa turma do $2^{\circ}$ ano de escolaridade
}

\author{
FILIPA VIANA
}

Universidade Aberta, Portugal. Laboratório de Educação a Distância e Elearning, LE@D. ORCID: https://orcid.org/0000-0003-4420-7196. E-mail: filipaviana87@gmail.com

\section{LÚCIA AMANTE}

Universidade Aberta, Portugal. Laboratório de Educação a Distância e Elearning, LE@D. ORCID: https://orcid.org/0000-0003-3210-7980.E-mail: lucia.Amante@uab.pt 


\section{O BLOGUE NA APRENDIZAGEM DA LINGUAGEM ESCRITA: estudo de caso numa turma do $2^{\circ}$ ano de escolaridade}

Investigar a forma como o blogue pode ser uma ferramenta potenciadora da aprendizagem da leitura e da escrita, constituiu o objetivo do trabalho que aqui apresentamos. $O$ estudo foi realizado numa escola de Lisboa, numa turma do $2 .^{\circ}$ ano do $1 .^{\circ}$ Ciclo do Ensino Básico, onde se iniciou uma atividade semanal - a Biblioteca de Turma. Aliada à atividade de leitura surgiu a criação de um blogue para partilha das leituras e trabalhos realizados pelas crianças ao longo do ano letivo. Procurámos analisar como a utilização do blogue para a publicação de trabalhos produzidos, pode ser uma mais-valia na criação de dinâmicas de trabalho significativas e relevantes na aprendizagem da leitura e da escrita. Adotámos uma metodologia de natureza qualitativa neste estudo de caso que assumiu o formato de investigação-ação. Concluímos que a utilização de meios tecnológicos como o blogue se revelou bastante motivadora da aprendizagem da linguagem escrita no grupo de crianças considerado, contribuindo para o desenvolvimento de competências nesta área e ainda para a aproximação e fortalecimento da relação da escola com as famílias.

Palavras chave: Blogue. Biblioteca de Turma. Leitura. Escrita. Crianças. Aprendizagem.

\section{THE BLOG IN THE LEARNING OF WRITING LANGUAGE: case study in a class of the 2nd year of schooling}

Research how the blog can be a tool that enhances the learning of reading and writing, was the objective of the work presented here. We conducted a study in a 2nd year class of the 1st Cycle of Basic Education, where we started a weekly activity - the Class Library. Allied to the activity of reading came the creation of a blog to share the readings and works done by the children throughout the school year. We have tried to analyze how the use of the blog for the publication of children works can be an added value in the creation of significant and relevant work dynamics in reading and writing learning. We adopted a methodology of qualitative nature in this case study that assumed the action-research format. We concluded that the use of technological means such as the blog proved to be quite motivating to learn written language in the group of children considered, contributing to the development of skills in this area and also to the connection and strengthening of the relationship between the school and the families.

Keywords: Blog. Class Library. Reading. Writing. Children. Learning.

\section{LE BLOG DANS L'APPRENTISSAGE DE LA LANGUE ÉCRITE: étude de cas dans une classe de 2e année de scolarité}

L'objectif du travail présenté ici était d'explorer comment le blog pouvait être un outil d'apprentissage de la lecture et de l'écriture. Nous avons mené une étude dans une classe de 2e année du ler cycle de l'éducation de base, où nous avons lancé une activité hebdomadaire - la bibliothèque de classe. Parallèlement à l'activité de lecture, un blog a été créé pour partager les lectures et les travaux réalisés par les enfants tout au long de l'année scolaire. Nous avons essayé d'analyser en quoi l'utilisation du blog pour la publication d'œuvres 
produites peut constituer une valeur ajoutée pour la création de dynamiques de travail significatives et pertinentes dans l'apprentissage de la lecture et de l'écriture. Nous avons adopté une méthodologie de nature qualitative dans cette étude de cas qui a adopté le format de recherche-action. Nous avons conclu que l'utilisation de moyens technologiques tels que le blog s'avérait très motivante pour apprendre la langue écrite dans le groupe d'enfants considéré, contribuant ainsi au développement des compétences dans ce domaine ainsi qu'au rapprochement et au renforcement des relations entre l'école et les familles.

Mots-clés: Blog. Bibliothèque de Casse. Lecture. Ecriture. Enfants. Apprentissage. 


\section{O BLOGUE NA APRENDIZAGEM DA LINGUAGEM ESCRITA: ESTUDO DE CASO NUMA TURMA DO 2 ANO DE ESCOLARIDADE}

\section{Introdução}

A aquisição da linguagem escrita constitui uma aprendizagem essencial. Fundamental para comunicar, fundamental para pensar, ela determina, em grande parte, o sucesso escolar nas mais diversas áreas, pelo que a sua aprendizagem assume particular relevância. Considerando a sociedade marcadamente tecnológica em que vivemos, esta aprendizagem não pode ignorar os contributos dos média digitais e as suas potencialidades.

A aprendizagem da leitura e da escrita, no $1 .^{\circ}$ Ciclo, é muitas vezes rotineira e repetitiva. $\mathrm{O}$ desenvolvimento desta aprendizagem é feito quase sempre através de leituras de textos dos manuais escolares, de cópias ou de composições pouco interessantes para os alunos, tornando-se um processo algo mecânico, geralmente pouco motivador para as crianças. Como professores colocámo-nos a seguinte questão: poderá o desenvolvimento de um blogue levar os alunos a ler mais e a entusiasmaremse para fazer trabalhos em redor de atividades que envolvem a linguagem escrita?

É indiscutível, como sabemos, a importância dos primeiros anos de escola no futuro pessoal e profissional da criança. É também inquestionável, nesses anos, a importância da aprendizagem da leitura e da escrita como uma das ferramentas indispensáveis à plena integração e participação dos indivíduos na sociedade. Sabe-se que o sucesso escolar e pessoal e a vida em sociedade, nomeadamente a autonomia do cidadão, dependem, em grande parte, do desenvolvimento de competências ao nível da linguagem escrita (BORGES, 1998). Deste modo, a leitura e a escrita são ferramentas necessárias para tarefas tão simples como: ir às compras, andar de transportes públicos, ir a um restaurante, pagar uma conta, fazer uma inscrição, registar um número de telefone, ou escrever uma mensagem. Assim, é lendo que se adquire grande parte das informações consideradas indispensáveis, tanto no cumprimento das funções profissionais e sociais como nas pequenas tarefas do dia-a-dia. Mas, para lá do papel funcional da linguagem escrita, não esqueçamos que só o seu domínio permite o desenvolvimento de uma cidadania informada. E, é igualmente no ato de ler que, por vezes, se abrem as portas a uma dimensão tão importante, como é a da imaginação e criatividade (SANTOS, 2000).

É pois fundamental dotar as crianças e os jovens de competências de leitura e de escrita, no sentido de tornar esses comportamentos de "leitor/escritor" ferramentas cognitivas ao serviço do seu desenvolvimento pessoal e social. Para tal, é preciso que o ato de ler figure entre as atividades mais 
comuns do seu quotidiano e do quotidiano daqueles que as rodeiam (SANTOS, 2000). Assim sendo, propusemo-nos criar situações de aprendizagem que promovessem o desenvolvimento de uma aquisição contextualizada de regras, normas e procedimentos relacionados com a estrutura, organização e coerência textual num circuito de comunicação, para o qual foi essencial o recurso ao potencial de ferramentas tecnológicas como o blogue (VIANA, 2018). Com a sua ajuda e através da partilha que esta ferramenta permite, procurámos levar as crianças a desenvolver um sentido social para a escrita e para a leitura, motivando-as para a sua aprendizagem.

\title{
A iniciação à leitura
}

Primeiramente, o conceito de leitura foi entendido como a capacidade de identificar os símbolos gráficos, aos quais correspondem os sons. Nos dias de hoje, o conceito de leitura implica a existência de duas componentes essenciais: a descodificação e a compreensão. $\mathrm{Na}$ descodificação, o leitor consegue automatizar a leitura, não necessitando de recorrer à soletração para ler; na compreensão ele lê palavras, frases e textos, construindo sentidos: ele interpreta os textos e utiliza a mensagem para construir e adquirir conhecimentos. Segundo, Colomer e Camps, a leitura é mais do que um ato mecanizado de descodificar:

\begin{abstract}
Um ato de raciocínio, já que se trata de saber orientar uma série de raciocínios no sentido da construção de uma interpretação da mensagem escrita a partir da informação proporcionada pelo texto e pelos conhecimentos do leitor e, ao mesmo tempo, iniciar outra série de raciocínios para controlar o progresso dessa interpretação de tal forma que se possam detectar as possíveis incompreensões produzidas durante a leitura. (COLOMBER; CAMPS, 2002, p.31)
\end{abstract}

Deste modo, a leitura é um conjunto de processos complexos, em que cada leitor decifra um código e imprime um significado que é influenciado por um conjunto de competências e fatores. A leitura surge como "processo individual", afetado pela dimensão social do contexto em que ocorrer. Assim, é de toda a importância ter em conta os conhecimentos prévios que o leitor possui sobre um determinado assunto e a interação com o suporte de leitura para conseguir informação extralinguística que facilite dar sentido ao que se lê (SARDINHA, 2008). De acordo com Azevedo entende-se a leitura como a faculdade de compreender e interpretar mensagens, possibilitando dar opinião e atribuir significado àquilo que se leu, "o ato de ler implica comunicar, entrar em diálogo com o escrito: concordar, discordar, conseguir informações necessárias para realizar algo, obter distração, prazer, companhia..." (AZEVEDO, 2006, p. 33) 
O conceito da leitura tem sofrido uma mutação ao longo dos tempos resultante da evolução das sociedades e dos estudos desenvolvidos no âmbito da psicologia da aprendizagem. Deste modo, nos dias de hoje, a leitura é encarada como um ato que envolve decifração e compreensão, em que o leitor poderá influenciar o significado do texto, tendo em conta, as inferências que poderá fazer de acordo com a sua vivência pessoal. Como refere, Sim-Sim (2006), a essência da leitura é a construção do sentido de um texto escrito e, aprender a compreender textos é o grande objetivo do ensino da leitura.

Em suma, o ato de ler não é apenas uma técnica de decifração de um código escrito. De um ponto de vista mais abrangente e integrador o ato de ler é também compreender, refletir, pensar, imaginar e criar. Uma leitura fluente resulta da interação de todas estas operações, o que a torna numa atividade psicológica particularmente complexa (VIANA; TEIXEIRA, 2002).

\section{Estratégias de motivação para a leitura}

Se a leitura é uma aprendizagem determinante no desenvolvimento da criança, para que ocorra é fundamental que haja motivação e se reúna um conjunto de condições que permita que esta aprendizagem seja construída com significado assumindo sentido para a criança. Assim, aprende-se a ler lendo e para se conseguir ser um bom leitor é preciso estar motivado e atribuir significado e prazer a este ato. Segundo Viana "o primeiro objetivo deverá ser o de conquistar leitores para, posteriormente, os formar" (VIANA, 2009, p. 32), pelo que é fundamental que se promova a leitura desde cedo. Desta forma, o contacto com os livros e com a leitura deverá começar em casa, ouvindo histórias lidas pelos familiares, observando os adultos a ler jornais, livros, etc. Este contacto precoce contribui para que a criança vá atribuindo significado e prazer ao ato de ler, desejando também ela saber ler, sentido esse ato como algo que a valoriza e que a aproxima do comportamento dos adultos que tem como modelo.

$\mathrm{Na}$ verdade, como defendem Santos et al. (2009), um bom leitor forma-se lendo, lendo muito e para que estes estímulos tenham efeito no desenvolvimento de pequenos leitores, é fundamental que estes gostem muito do que leem. Assim, quer a existência de leitores em casa, quer o papel diário do educador de infância e das interações que estabelece com as crianças a propósito do código escrito, constituem uma fonte inesgotável e preciosa de estímulos para esta aprendizagem (SIM-SIM; NUNES, 2008).

Depois da fase de estimulação inicial, que deverá começar em casa e ser reforçada no Jardim de Infância, a Escola desempenhará também um papel preponderante na iniciação à leitura. Este processo de iniciação à leitura nos primeiros anos de escola deve ser alvo de constante 
reconhecimento, de forma a motivar e incentivar a criança a prosseguir. Para incentivar os alunos à leitura o papel do professor é fulcral. Assim, importa ir ao encontro do que lhes interessa, respeitando o seu ritmo e proporcionando exemplos, ou seja servindo de modelo para que as crianças possam desenvolver o seu projeto de "leitores/escritores" (MARTINS; NIZA, 2014).

\section{A escrita}

Comparada com a fala, a escrita está longe de ser uma atividade natural. Enquanto a fala é uma caraterística universal e biologicamente determinada, a escrita é social e culturalmente acessível. Como refere Liberman (1996) para adquirir a fala basta pertencer à espécie humana e ser exposto à língua de determinado povo. Mas, para aprender a ler e a escrever é preciso somar a estas condições uma terceira, o ensino da linguagem escrita. Embora do ponto de vista da criança as duas formas de linguagem tenham de ser aprendidas, a escrita exige uma aprendizagem mais formal. Não lhe é suficiente já ter algum domínio da linguagem falada e ser exposta a materiais escritos, é também necessário que a criança descubra as convenções que organizam a escrita.

Mas, ao longo do percurso de aprendizagem, a criança constrói conceitos sobre a linguagem escrita e manifesta comportamentos percursores das práticas de leitura convencionais. Muito antes da chegada à escola, a criança já tem presente algumas ideias sobre: "o que é escrever?", "para que serve?", etc. Estes pré-conceitos da criança tratam-se de ideias não convencionais sobre as funções e as propriedades da escrita e sobre o que esta representa e são fundamentais do ponto de vista cognitivo para o início da sua aprendizagem formal. (MARTINS; NIZA, 2014)

\section{A promoção da escrita através da partilha}

Nas palavras de Eveline Charrmeux (1994), a produção de um texto é "uma atividade sócio psicolinguística", isto é, a escrita é uma atividade de elaboração linguística que se dirige a um recetor num suporte social (carta, aviso, cartaz, texto, recado, receita, etc.). Assim sendo, é fundamental que o professor crie situações de aprendizagem que promovam o desenvolvimento de uma aquisição contextualizada de regras, normas e diversos circuitos de comunicação. É pois determinante que os alunos desenvolvam e construam um sentido social para a escrita. Desta forma, os alunos devem compreender a funcionalidade comunicativa da escrita, a partir de atividades que trabalhem diferentes tipos de texto e diferentes finalidades comunicativas.

\section{A utilização de ferramentas digitais na promoção da leitura e da escrita}

Se a sociedade atual dá cada vez mais relevância às tecnologias é importante que a Escola não se desligue desta nova realidade e que também ela use o potencial das tecnologias digitais para 
melhor cumprir a sua função, ou seja promover a aprendizagem das crianças. Com efeito, utilizar os meios tecnológicos pode ser uma forma inovadora e relevante para tornar a aprendizagem significativa e não obsoleta. Muitas vezes o ensino não é suficientemente motivador ou apelativo e é preciso contornar este handicap e permitir que os alunos possam interagir com ferramentas digitais que podem potenciar a sua aprendizagem e integração numa sociedade cada vez mais digital. Como referido por Amante, (20011, p.83),

\begin{abstract}
a utilização das tecnologias, designadamente a utilização dos programas de processamento de texto, bem como a utilização de ferramentas de comunicação como o correio electrónico, ou o uso de ferramentas da Web social, como os blogues, estimulam a utilização do código escrito e proporcionam situações de interacção com práticas de escrita, que se constituem como experiências educativas para o desenvolvimento da literacia, especialmente ricas e motivadoras.
\end{abstract}

Com efeito, a utilização de ferramentas digitais como forma de publicar os seus trabalhos permite que os alunos escrevam para os outros, levando-os a descobrir a funcionalidade e finalidade da escrita. Segundo Santana "A comunicação é, nesta perspetiva, o motor da escrita, favorecendo progressivas aproximações do aluno a um discurso escrito socialmente dirigido" (SANTANA, 2007, p. 82) que se traduzirá num efeito comunicativo de interação e partilha com os outros.

A escola e o professor têm um papel fundamental na aprendizagem dos seus alunos, sendo esta um reflexo do seu trabalho. O papel do professor deverá ser o de orientador do percurso dos alunos, levando-os à descoberta e construção de aprendizagens significativas inseridas no seu quotidiano e na sua realidade.

Como salienta Santana:

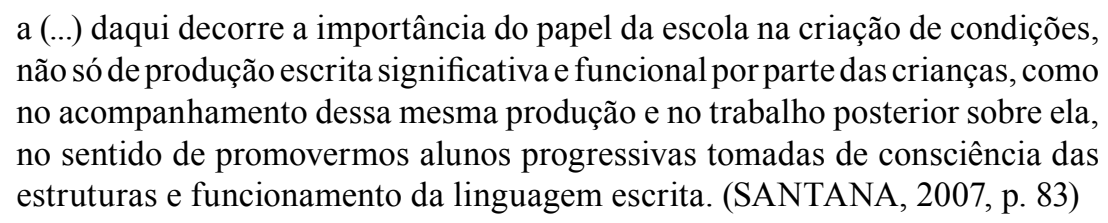


Neste sentido, o professor deverá criar momentos para que as crianças possam escrever para comunicar e, nos dias de hoje, é imperativo que o professor retire vantagem da utilização de ferramentas digitais em sala de aula para potenciar essa comunicação, mas também para realizar uma pesquisa rápida com os alunos sobre um tema que surge no decurso da aula, ou para explorar diversos recursos existentes na internet que permitem ampliar a sala de aula para o mundo.

\section{Uso do blogue em contexto educacional}

A questão inovadora da partilha com os outros daquilo que fazemos, está na base da ideia da criação dos blogues. Podemos dizer que a ideia de partilha constitui a sua matriz. Segundo, Orihuela e Santos (2004) existem três vantagens na utilização de blogues: a criação e o manuseamento das ferramentas de publicação é fácil; as interfaces disponibilizadas permitem ao utilizador centrar-se no conteúdo e apresentam ainda funcionalidades como comentários, arquivo, etc.

Nos dias de hoje fala-se em blogosfera, sendo esta constituída pelos milhões de blogues que têm invadido a internet; também se ouve a expressão blogomania, que põe em evidencia o imenso número de blogues que são criados diariamente, em todo o mundo e o seu uso intensivo. Os blogues podem ser pessoais ou coletivos e podem estar abertos a todos ou serem privados a uma comunidade fechada, a qual discute temas específicos de interesse para esse grupo ou comunidade. Assim, hoje em dia, os blogues tornaram-se uma forma de expressar opiniões e a maioria dos usuários não os utiliza como diário, mas sim como partilha de informação, sugestões ou opinião. As temáticas também são cada vez mais variadas: política, moda, desporto, religião, educação, viagens, todo e qualquer assunto pode ser o tema de um blogue.

Desta forma, a utilização de meios digitais na educação e aprendizagem passou a ter este novo meio disponível, ainda que na sua origem não tenham estado objetivos educacionais. Não obstante, os blogues são considerados uma ferramenta facilitadora de interação, pois, segundo Barbosa e Granado (2004), podem ajudar alunos e professores a comunicar mais e melhor, sobre determinados temas facilitando a aprendizagem. Como é salientado por estes autores, a partilha de textos é uma porta aberta para a troca de experiências com outras escolas, outros professores e alunos, outras realidades.

De acordo com Gomes (2005), a blogosfera educacional é cada vez mais transversal e contempla todos os níveis de ensino: vai do pré-escolar ao ensino superior. Podemos dizer que o blogue é um recurso e uma estratégia utilizada em diferentes níveis, contudo a sua exploração 
pode ser diversa, adaptada ao que é pretendido pelo professor junto dos seus alunos. Ainda de acordo com Gomes (2005) na exploração dos blogues como estratégia pedagógica, o papel dos alunos na sua criação e dinamização torna-se central e fulcral. Tendo como suporte tecnológico os blogues, os alunos são chamados a construir, analisar, selecionar, sintetizar e publicar online a informação sobre as atividades em curso, com a orientação do professor.

A criação e dinamização de um blogue, segundo esta perspetiva, cria condições facilitadoras e motivadores do desenvolvimento de múltiplas competências quer no campo do domínio das Tecnologias da Informação e Comunicação e da pesquisa de informação, quer ao nível das competências de comunicação escrita.

O blogue constitui, assim, não só uma ferramenta de publicação, mas, também, uma ferramenta de comunicação permitindo o desenvolvimento de projetos de colaboração e partilha, mas, também, de debate. O facto de o blogue ser um meio online permite que seja amplamente visionado e comentado, fomentando a interação e a partilha no universo da Web. Esta "vivência em rede" confere aos contextos de aprendizagem uma dimensão social facilitadora de interações (AMANTE; FARIA, 2013) e como tal promotora de aprendizagens.

O blogue tem vindo a assumir cada vez mais o papel de objeto de aprendizagem, sendo utilizado frequentemente com grande entusiasmo (OLIVEIRA, 2005). Com efeito, os professores têm vindo a tirar partido desta ferramenta, e aos poucos os blogues educacionais foram adquirindo visibilidade, sendo atualmente perspetivados como importantes recursos e estratégias pedagógicas.

\section{Metodologia}

O presente trabalho teve como principal objetivo investigar a forma como o blogue pode ser uma ferramenta potenciadora da aprendizagem da leitura e da escrita. Nessa perspetiva, foi realizado um estudo, numa turma do $2 .^{\circ}$ ano do $1 .^{\circ}$ Ciclo do Ensino Básico, composta 16 meninas, em que se iniciou uma atividade semanal - a Biblioteca de Turma, envolvendo a criação de um blogue para partilha das leituras e trabalhos realizados pelas crianças ao longo do ano letivo. Aliado ao objetivo principal do estudo surgiram outros objetivos mais específicos, como por exemplo: potenciar a motivação para a leitura de livros de histórias; promover o desenvolvimento da escrita de pequenos textos; estimular o envolvimento dos pais nas atividades da escola; desenvolver competências ao nível da utilização das tecnologias (VIANA, 2018). 
Delineámos um plano de intervenção que contemplava diversas atividades em redor do blogue para atingir os objetivos que nos propusemos. Para avaliarmos a consecução dos mesmos recorremos a uma metodologia de natureza qualitativa. O investigador está interessado no sentido que os sujeitos observados dão à realidade em estudo, tentando apreender as suas perspetivas pessoais (BOGDAN \& BIKLEN, 1994).

Dado o contexto em que atuámos e os nossos objetivos, a pesquisa assume-se como um estudo de caso com uma vertente exploratória e descritiva (COUTINHO; CHAVES, 2002). Nesta investigação, o caso em estudo foi a turma do $2{ }^{\circ}$ ano $\mathrm{B}$, de uma escola privada da região de Lisboa, escolhida por ser a turma em que a investigadora atuava como professora titular. Assim, tratou-se de um estudo de caso único (YIN, 2001), intrínseco (STAKE, 2007), visto que o objetivo da investigação é o de compreender melhor esta realidade em particular. O trabalho de campo foi realizado através da observação direta, registada no Diário de Bordo, que constituiu um instrumento fundamental desta pesquisa. Recorremos ainda a questionários e entrevistas de grupo às crianças da turma e análise das suas produções como forma de complementar a nossa recolha de dados. A análise realizada aos registos de observação e às entrevistas seguiu os procedimentos característicos da análise de conteúdo (VALA, 1986).

No entanto, como professora da turma, a investigadora não se limitou a investigar, mas também foi interveniente na realidade observada. Este duplo papel do professor, enquanto ator educativo e investigador, está diretamente ligado ao caráter prático da investigação-ação e ao seu objetivo de resolver problemas reais como aqueles com que os professores se confrontam na sua atividade diária. Implicam-se assim os professores na reflexão e na produção de saberes sobre a sua profissão, articulando investigação e intervenção (BENAVENTE et al, 1990).

No caso presente, a investigadora enquanto professora da turma refletiu sobre a sua prática docente, tentando encontrar estratégias de trabalho que permitissem promover as aprendizagens de todos os alunos, ultrapassando as dificuldades sentidas. Estamos assim perante uma investigação-ação, caraterizada segundo Coutinho et. al (2010), por se tratar de uma metodologia de pesquisa essencialmente prática e aplicada que se rege pela necessidade de resolver problemas reais. Neste caso, promover uma maior motivação para a aprendizagem da linguagem escrita na turma em questão.

\section{Descrição e análise de atividades desenvolvidas}

No início do ano letivo 2015/2016 as alunas foram informadas da continuidade da atividade da Biblioteca de Turma. Esta atividade tinha começado no ano letivo anterior ( $1^{\circ}$ ano do $\left.1^{\circ} \mathrm{CEB}\right)$ 
embora em moldes um pouco diferentes. No ano anterior, cada aluna trazia um livro para a Biblioteca indicado pela professora, de acordo com o Plano Nacional de Leitura ${ }^{1}$. As alunas quinzenalmente trocavam os livros entre si e elaboravam uma ficha de leitura. A ficha era muito simples pedindo a cópia de uma frase do livro e a ilustração da parte preferida da história. Esta atividade correu muito bem e as crianças participaram ativamente demonstrando entusiasmo e gosto pela leitura e pela apresentação às colegas dos seus trabalhos.

No início do $2 .^{\circ}$ ano foi apresentada a continuidade da atividade mas com a novidade do recurso às TIC, nomeadamente ao blogue. A atividade começou da mesma forma, tendo a professora indicado um livro a cada criança tendo em conta o ano de escolaridade. O primeiro trabalho foi realizado em coletivo, como se pode verificar pelo excerto do Diário de Bordo:

Excerto 1 - Diário de Bordo.

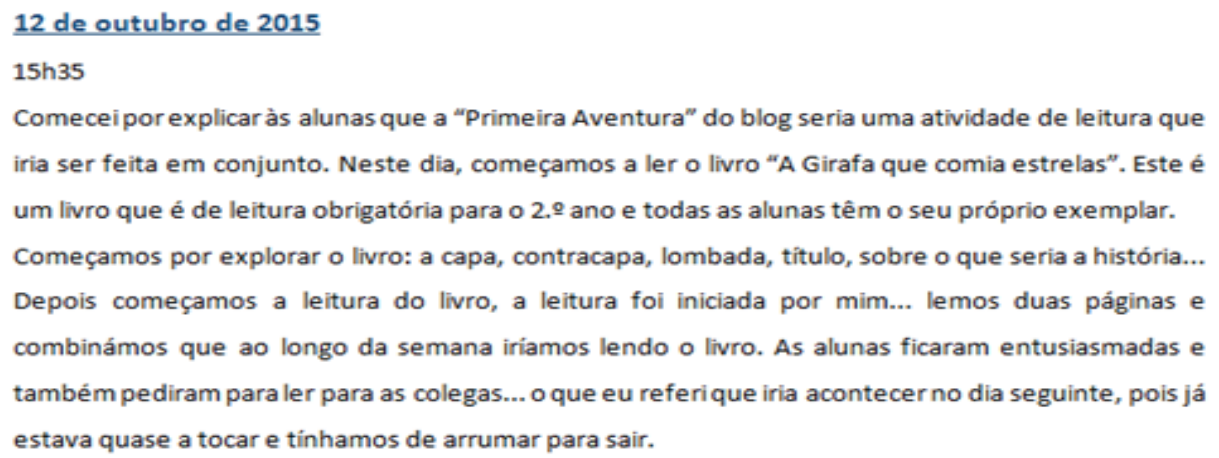

Depois de lido o livro em coletivo foi dividido em diferentes partes e cada grupo ficou responsável por resumir uma parte da história e fazer a sua ilustração. Depois de finalizada esta

\footnotetext{
${ }^{1}$ Plano Nacional de Leitura - O Plano Nacional de Leitura foi implementado pelo Governo Português em 2006 e constitui uma iniciativa de política pública que visa elevar os níveis de literacia da população portuguesa. Pretende fomentar hábitos de leitura e desenvolver competências de literacia da população em geral, mas particularmente, das crianças e jovens em idade escolar (COSTA; PEGADO; ÁVILA e COELHO, 2011).
} 
primeira etapa começava a grande aventura informática, a construção de um blogue da turma para partilha dos trabalhos. Esta foi sem dúvida uma das etapas mais entusiasmantes para as crianças pois a descoberta do blogue (cores, imagens, tipos de letras, etc.), bem como a perceção das suas funcionalidades, designadamente a partilha com os outros através de um clique, constituiu um estímulo assinalável. Nesta primeira fase, o principal objetivo era proporcionar um primeiro contato entre as crianças e o blogue, permitindo uma familiarização com a ferramenta para posterior exploração de forma cada vez mais autónoma. Depois de publicado o primeiro trabalho, todas quiseram ver de perto a produção do seu grupo e iam comentando: "este é o vosso desenho", "que lindo este desenho!", “adoro o vosso trabalho!", "este é o nosso, está tão giro!", etc. À medida que iam observando foi preocupação da professora/investigadora que todas as alunas fossem contactando com o computador explicando-lhes tudo o que era feito e como, criando assim familiaridade com os passos realizados na publicação de um trabalho no blogue.

Autores como Ponte (2002, p.2) há muito que defendem que "Na escola, as TIC são um elemento constituinte do ambiente de aprendizagem. (...) Permitem a criação de espaços de interação e partilha pelas possibilidades que fornecem de comunicação e troca de documentos." constituindo uma ferramenta de apoio ao trabalho do professor que permite o desenvolvimento de diferentes competências e que estimula o espírito criativo. A criação do blogue no caso da turma em análise inscreve-se nesta perspetiva, permitindo às crianças o acesso a uma ferramenta que lhes permitiu desenvolver competências específicas no que se refere à aprendizagem da linguagem escrita estimuladas pela partilha e visibilidade dos trabalhos que esta ferramenta propicia.

Depois da primeira atividade ter sido feita em coletivo como ponto de partida, chegou a altura de distribuir livros pelas crianças e no período de quinze dias cada uma deveria ler um livro e realizar uma ficha de leitura (Figura 1). 
Figura 1. Ficha de leitura.

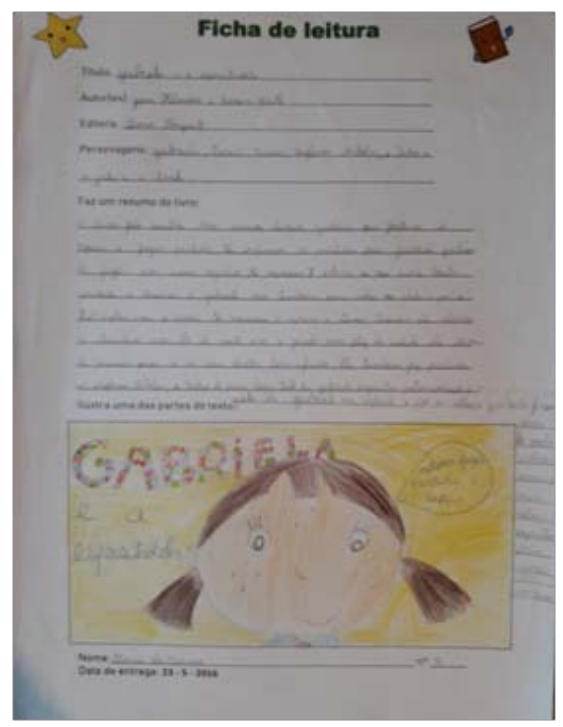

Fuente: autoras.

Depois de concluídas as fichas de leitura, no dia estipulado, as crianças apresentavam os seus trabalhos e o grupo votava nos que mais gostava. Eram assim escolhidos os trabalhos a serem publicados no blogue. Estes eram passados pelas autoras com a ajuda de colegas que ditavam ou auxiliavam na escrita no processador de texto. Depois de realizado todo este processo em coletivo as crianças, com o auxílio da professora, publicavam no blogue os novos trabalhos e visionavam os comentários deixados ao trabalho anterior. Desta forma, as crianças foram parte ativa no processo sendo o professor um orientador do trabalho realizado e condutor da atividade auxiliando e explicando todos os passos para que a turma fosse cada vez mais autónoma na gestão do blogue.

\section{Análise do diário de bordo}

Para o presente estudo, procedeu-se então à análise das notas de campo reunidas no Diário de Bordo da professora/investigadora. Passa-se a apresentar uma seleção das principais categorias temáticas que emergiram dos dados, com base em alguns exemplos de excertos do Diário de Bordo, bem como uma breve reflexão sobre os resultados que essa análise evidenciou. 
Papel do Professor - Ao longo de toda a investigação o professor teve um papel de orientador do percurso das alunas e de condutor da atividade, levando as crianças à descoberta $\mathrm{e}$ à construção de aprendizagens. O professor/investigador tentou tornar a atividade na Biblioteca de Turma numa mais-valia para a construção de novos saberes curriculares e tecnológicos. A atividade apostava na partilha, diálogo, conversação, permitindo que todos se sentissem parte integrante do projeto. Assim, muitas das atividades partiram de ideias que foram surgindo em contexto de sala de aula, como testemunha o excerto do Diário de Bordo que se segue.

Excerto 2 - Diário de Bordo (21/10/2015).

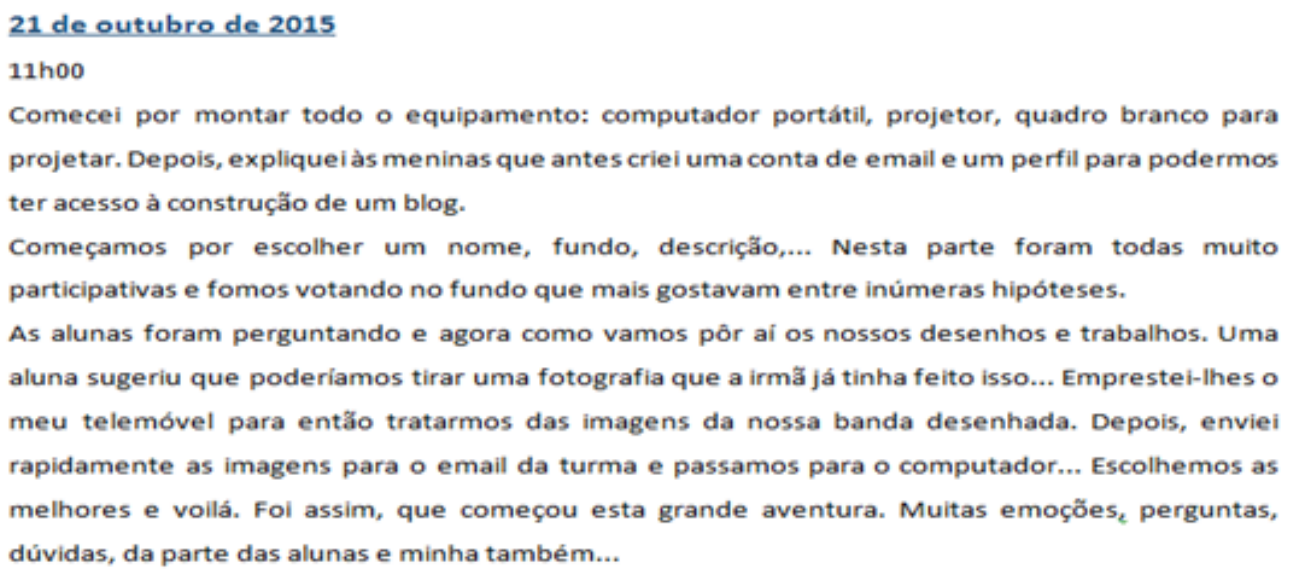

Gestão de Conflitos - O trabalho colaborativo a pares ou em grupo realizado ao longo da investigação é um ponto fundamental pois sabemos como a partilha e a discussão podem potenciar o desenvolvimento da aprendizagem das crianças (VIGOTSKY,1984), embora nem sempre seja um trabalho fácil. Cabe ao professor ajudar os grupos de crianças a saber partilhar ideias levando-as a chegar a um consenso como se percebe nesta passagem do Diário de Bordo. 
Excerto 3 - Diário de Bordo (16/10/2015).

\begin{abstract}
sempre que existe alguma dúvida ou algumas meninas que entram em discussão sobre o que têm que fazer. Este é um grupo de meninas e algumas têm ainda alguma dificuldade em trabalhar em grupo e chegar a um consenso sem a minha ajuda e insistência para dialogarem. Depois de tudo feito a lápis, reunimos em coletivo para lermos as falas e vermos a sequencia de imagens... se fazia
\end{abstract}

Nesta fase constatámos ser muito importante que o professor esteja muito atento e ajude a desbloquear os conflitos que surgem nos trabalhos em grupo. À medida que o ano letivo foi decorrendo os trabalhos de grupo começaram a fluir cada vez mais e a ajuda do professor começou a ser mais pontual e os grupos passaram a ser mais autónomos. A turma foi evoluindo e a pouco e pouco a sua autonomia foi crescendo bem como o nível de reflexão e análise ao trabalho realizado por cada criança.

Excerto 4 - Diário de Bordo (14/3/2016).

A apresentação dos trabalhos correu muito bem, embora seja um pouco longa, pois todas gostam de
apresentar e de comentar, tive de gerir um pouco os comentários e para cada trabalho havia no
máximo três comentários, para não se prolongar ainda mais. Parece-me que é nesta fase de diálogo
e de comentários que se nota uma maior reflexão das alunas perante a escrita e leitura, aproveitei
também para lhes explicar que os comentários dos outros são muito importantes para nos ajudarem
a melhorar e a refletir o que fazemos melhor e pior. Sinto que as alunas têm evoluído muito e
sentem que os comentários das colegas são importantes, tanto quanto os meus.

Motivação para a Aprendizagem - O principal objetivo deste trabalho foi a promoção da leitura e da escrita através da utilização do blogue enquanto ferramenta de partilha e de motivação para a aprendizagem. Esta partilha com as colegas e com a comunidade educativa foi sem dúvida uma mais-valia para a atribuição de um significado à escrita. Como refere Mata (2008) escrever para os outros permite a atribuição de um significado social à escrita, bem

\title{
plu[ais Salvador, v.4, n.2 p.94-116, mai./ago. 2019
}


como à leitura por parte do outro que lê. Ao longo do ano letivo as alunas foram crescendo e foram fazendo comentários e sugestões cada vez mais enriquecedores, conforme se constata na passagem seguinte do diário de bordo.

Excerto 5 - Diário de Bordo (14/3/2016).

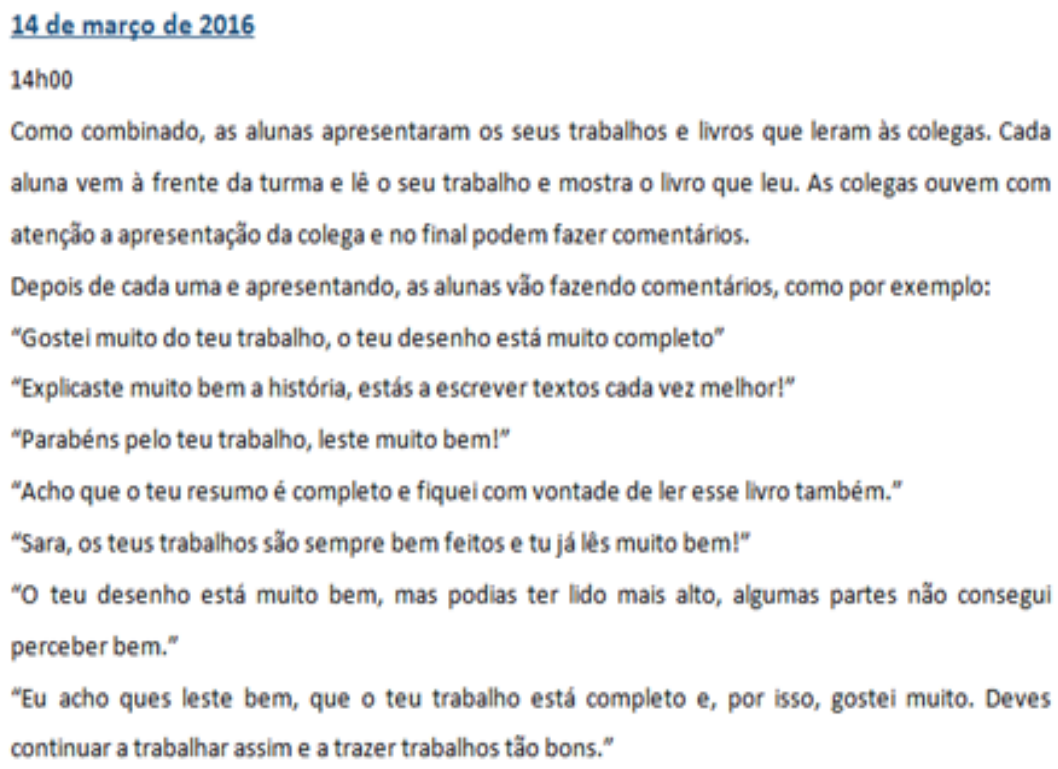

Famílias - A partilha com os outros através do blogue como uma ferramenta facilitadora da interação entre a escola e a família foi um dos pontos fortes desta atividade. A importância da partilha na aprendizagem é uma característica vital, pois as alunas ao longo da atividade ansiavam sempre por partilhar os seus trabalhos, numa primeira fase para mostrar aos seus pais, noutra fase para mostrar aos colegas e a toda a comunidade educativa. Os comentários das famílias foram muito importantes para gerar motivação. Depois da publicação dos trabalhos as crianças pediam sempre aos pais em casa para irem visitar o blogue e deixar um comentário à publicação feita. 
Excerto 10 - Diário de Bordo (28/4/2016).

\section{8 de abril de 2016}

Fomos novamente ao blogue porque a Sara disse que o pai já tinha comentado, vimos o comentário e as alunas ficaram muito contentes:

"Olá a todas, gostei muito dos vossos comentários sobre as histórias e certamente irei ler alguns destes livros. Vou ficar muito atento aos vossos trabalhos. Um beijinho para todas." Nuno Gomes

Deste modo, os comentários feitos pelos pais ajudaram a motivar a turma para a realização de outros trabalhos a publicar no blogue. As alunas passaram a sentir que o seu trabalho era reconhecido, apreciado e lido fora da escola, o que constituía um motivo de orgulho. Segundo Costa (2010) a utilização de ferramentas digitais é um impulsionador de mudança na escola surgindo como um estímulo para a aprendizagem. Assim, os comentários no blogue possibilitaram que as alunas se sentissem valorizadas e intervenientes no processo ensino-aprendizagem dado que os seus trabalhos não eram realizados só para serem avaliados pela professora mas podiam ser partilhados e ser alvo de interesse para uma comunidade mais alargada de pessoas significativas para as crianças.

Depois da leitura do livro "A Fada Oriana" de Sophia de Mello Breyner Andersen, as alunas escreveram o reconto, seguido da construção das personagens e cenários da história. Compilados todos os elementos e com a ajuda da professora animaram o vídeo e escolheram as mudanças de cenários e a introdução de vozes. Todo este processo exigiu uma grande colaboração entre toda a turma e o resultado final foi sentido como verdadeiramente coletivo. O grande número de comentários feitos a este trabalho fez crescer um sentimento de orgulho e de felicidade entre as alunas por terem realizado um trabalho que tanto gostaram e que viam assim reconhecido pelos outros. Esta satisfação é muito importante e permite que as crianças gostem de ir para a escola e de estar na escola, sendo esse sentimento fundamental para o sucesso na aprendizagem.

No excerto 10, apresentamos comentários dos pais ao trabalho coletivo sobre o livro "A Fada Oriana": 
Excerto 11 - Diário de Bordo (29/6/2016).

\section{Reorganiza23 dejunhode 2016 às 13:58}

Meninas queridas! É muito bom ver os vossos trabalhos. São uma turma de meninas muito queridas e bonitas. Continuem assim! E parabens a professora por ser tão boa e amiga :) Beijinho do pai Tim

\section{Nuno Gomes 27 dejunho de 2016 às 03:24}

Olá meninas! Aproveitei um intervalo no trabalho, agora durante a manhã para ver e ouvir a vossa histónia da fada Oriana. Adorei cada bocadinho, foi enriquecida com muita imaginação. Fico a aguardar mais histónias vossas e estão todas de parabéns! Muitos beijinhos para todas do pai Nuno. (Pai da Sara)

\section{Dulce O'Neill 27 de junho de 2016 às 03:35}

Queridas Meninas,Muitos parabéns por um ano cheio de trabalho e de tanto esforço. Mas os resultados estão à vista: o vosso Blog é hiper-super-mega fantástico! Agora desejo a todas umas merecidas e descansadas férias de Verão, com muita praia e sol! Um beijinho da mãe da Madalena 0 .

\section{Gisela Cerqueira27 de junho de 2016 às 14:34}

Olá Princesas!Maravilhoso, foi um momento muito agradável, lêem todas muito bem e as ilustrações estão o máximo! Estão de Parabéns! Um obrigada à Professora Filipa pelo excelente trabalho que fez com estas fantásticas aprendizes! Boas férias a todas!!! Um beijinho da mãe da Sarocas

\section{Paulo Seixas da Fonseca20 de junho de 2016 às 13:41}

Muitos parabéns!!! Muito giro!!! A histónia é muito bonita e ensina uma lição muito importante: que nós nos devemos preocupar com os outros!! Se fizermos isso ganhamos assas para ir para o céu!!! Muitos parabéns à realizadora, daqui a dois anos pode mudar de profissão!! Pai da CarminhoSF

\section{Conclusões}

Ao longo da investigação as crianças foram evoluindo de forma satisfatória e foram lendo cada vez mais. Um dos principais objetivos da atividade Biblioteca de Turma era a promoção e consequente desenvolvimento do gosto pela leitura, objetivo alcançado com bastante sucesso. A leitura passou a estar presente no dia-a-dia da turma tanto na escola como em casa, uma vez que as alunas não falhavam a entrega dos livros e da ficha de leitura nos dias indicados. Deste modo, pode referir-se que o blogue foi um impulsionador da leitura e escrita neste grupo de crianças, 
a partilha com os outros e a atribuição de um sentido social à escrita foi fundamental para a sua aprendizagem e desenvolvimento.

A atividade da biblioteca de turma contribuiu para que as crianças realizassem novas aprendizagens de uma forma empenhada. Sentiram a sala de aula como um local seu em que as suas opiniões e produções eram consideradas e valorizadas. A escola deverá ser um local de troca e de partilha e não um local expositivo e de treino descontextualizado de competências, de memorização de conteúdos e conceitos, sem ter em conta a realidade e vivência das crianças.

A produção de um texto é "uma atividade sócio e psicolinguística" (CHARMEUX, 1999), isto é, a escrita é uma atividade de elaboração linguística que deverá ter uma intenção social. Assim, é muito importante que o ato de escrever seja trabalhado como uma componente social, que permite a comunicação com os outros. A escrita surge como uma ferramenta de comunicação, permitindo que desta forma as crianças atribuam um significado e sentido para o que estão a realizar, fazendo um texto para partilhar com os outros, dando a sua opinião sobre um determinado livro, tema ou assunto. Esta atividade permitiu que as crianças da turma percebessem a funcionalidade da escrita, enquanto promotora da comunicação e partilha com os outros daquilo que produzimos, bem como o seu potencial criativo e estético associado ao prazer da narrativa e da sua mensagem.

Para a professora a introdução de recursos digitais constituiu um desafio, uma vez que implicou uma constante evolução e preparação da sua atuação enquanto mediadora de toda a atividade letiva. Este papel de orientador da atividade requer uma entrega que desafia a tarefa do professor pondo à prova as suas competências, a sua capacidade de gestão do grupo-turma e de gestão dos recursos tecnológicos utilizados. Salientamos pois, tal como Oliveira (2005), que o blogue usado como recurso pedagógico, desenvolve o papel do professor como mediador na produção de conhecimento, favorecendo a integração da aprendizagem da leitura/escrita num contexto autêntico.

É assim também importante refletir, a partir da experiência proporcionada por este estudo, sobre as tecnologias digitais e o seu papel na aprendizagem das crianças, permitindo que todas possam ter acesso a uma experiência enriquecedora e que possibilite a aquisição de novas competências. Com efeito as tecnologias são instrumentos que possibilitam a interação entre toda a turma e, no caso do blogue, com uma comunidade educativa mais vasta, pais, irmãos, outras escolas. Permitem assim que a aprendizagem seja uma construção se saberes em coletivo, em que cada um pode dar o seu contributo que passa a ser valorizado por muitos outros. 
Deste modo, o blogue é uma ferramenta que poderá potenciar a criação de atividades motivadoras e enriquecedoras, permitindo que haja uma partilha de aprendizagens, permitindo que a sala de aula seja um local aberto e estimulante do envolvimento das crianças.

Numa sociedade em constante mutação tecnológica é necessário continuar a estudar e a desenvolver estudos nesta área, pois as tecnologias e o seu potencial pedagógico precisa ser cada vez mais explorado. $\mathrm{O}$ futuro urge e é necessário e imprescindível a mudança e a inovação das práticas pedagógicas, adaptando-as à realidade do nosso mundo atual.

\section{REFERÊNCIAS}

AMANTE, L. As Tecnologias Digitais na Escola e na Educação Infantil. Melo Editora: Pinhais - Curitiba (pp.176), 2011.

AMANTE, L.; FARIA, A. Escola e Tecnologias Digitais na Infância. In Patrícia L. Torres (org.) Complexidade: redes e conexões na produção de conhecimento, SENAR- Pr. Curitiba (pp. 255-284) 2013. https://www.agrinho.com.br/site/wp-content/uploads/2014/09/2_12_Escola-e-tecnologias-digitais.pdf

AZEVEDO, F. Língua Materna e Literatura Infantil - Elementos Nucleares para Professores do Ensino Básico. Lisboa: Lidel, 2006.

BARBOSA, E.; GRANADO, A. Weblogs, Diário de Bordo. Porto: Porto Editora, 2004.

BENAVENTE, A., COSTA A., \& MACHADO, F. Práticas de mudança e de intervenção - Conhecimento e intervenção na escola primária. Revista Crítica de Ciências Sociais, 29, fevereiro 1990, 55 - 80. 1990 .

BODGAN, R. \& BIKLEN, S. Investigação Qualitativa em Educação. Colecção Ciências da Educação. Porto: Porto Editora, 1994.

BORGES, T. M. Ensinando a ler sem silabar. Campinas: Papirus Editora, 1998.

CHARMEUX, E. Apprendre à lire: Échec à l'échec, Éditions Milan, 1999.

COLOMER, T. \& CAMPS, A. Ensinar a Ler Ensinar a Compreender. Porto Alegre: Artmed, 2002.

COSTA, F. A. Metas de Aprendizagem na área das TIC: Aprender Com Tecnologias. In Fernando Costa et al (2010), I Encontro Internacional TIC e Educação. Inovação Curricular com TIC. 
Lisboa. Instituto de Educação da Universidade de Lisboa. 931-936, 2010.

COSTA, A. F.; PEGADO, El. ÁVILA, P. COELHO, A. R. Avaliação do Plano Nacional de Leitura: Os primeiros cinco anos. CIES, Lisboa, 2011.

COUTINHO, C. P.; ALVES, M. C. F. Educação e sociedade da aprendizagem: um olhar sobre o potencial educativo da internet. Revista de Formación e Innovación Universitaria. p. 206-225, 2010.

COUTINHO, C.P. E CHAVES, J.H. O estudo de caso na investigação em Tecnologia Educativa em Portugal. In Revista Portuguesa de Educação, 15 (1), pp. 221-243. Braga: Universidade do Minho, 2002.

GOMES, M. J. Blogs: um recurso e uma estratégia pedagógica. VII Simpósio Internacional de Informática Educativa, 311-315,. Leiria: Escola Superior de Educação de Leiria, 2015.

LIEBERMAN, A. M. Speech: A Special code. Cambridge: MIT Press, 1996.

MARTINS. M. A. \& NIZA, I. Psicologia da Aprendizagem da Linguagem Escrita. Lisboa (2a edição) e-book: Universidade Aberta, 2014.

MATA, L. A descoberta da escrita. Textos de apoio para Educadores de infância. Lisboa: Direção-Geral de Inovação e de Desenvolvimento Curricular, 2008.

OLIVEIRA, R. M. Aprendizagem mediada e avaliada por computador: a inserção dos blogs como interface na educação, 2005. http://www.abed.org.br/congresso2005/por/pdf/026tcc5.pdf

ORIHUELA, J. L., SANTOS, M. L. Los weblogs como herramienta educativa: experiências com bitácoras de alumnos, in Quaderns Digitals, n³4, Outubro, 2004.

PENNAC, D. Como um Romance. Porto: Edições Asa, 1993.

PONTE, J. P. As TIC no início da escolaridade: Perspectivas para a formação inicial de professores. In J. P. Ponte (Org.) A formação para a integração das TIC na educação pré-escolar e no 1. ${ }^{\circ}$ ciclo do ensino básico, p. 19-26, Porto: Porto Editora, 2002.

SANTANA, I. A Aprendizagem da Escrita - estudo sobre a revisão cooperada de texto. Porto Editora, 2007.

SANTOS, E. M. Hábitos de leitura em crianças e adolescentes. Coimbra: Quarteto Editora, 2000. 
SARDINHA, M. Leitura na escola. A escola em leitura. In: Transversalidade da língua portuguesa: representações, instrumentos e práticas. Aveiro: Gráfica. 2008.

SIM-SIM, I. Ler e ensinar a ler. Porto: Edições Asa, 2006.

SIM-SIM, I., SILVA, A. C., \& NUNES, C. Linguagem e comunicação no jardim-deinfância: textos de apoio para educadores de Infância. Lisboa: Editorial do Ministério da Educação, Direcção-Geral de Inovação e Desenvolvimento Curricular, 2008.

STAKE, R. E. A arte da investigação com estudos de caso. Lisboa: Fundação Calouste Gulbenkian, 2007.

VALA, J. Análise de Conteúdo. In A. Silva, \& J. Pinto, (Org.). Metodologia das Ciências Sociais p. 507-535. Porto: Afrontamento, 1986.

VIANA, F. O blogue da biblioteca de turma na promoção da leitura e da escrita. Dissertação de mestrado em Supervisão Pedagógica. Universidade Aberta, 2018. https://repositorioaberto.uab. $\mathrm{pt} / \mathrm{handle} / 10400.2 / 7895$

VIANA, F. L., TEIXEIRA, M. M. Aprender a ler: da aprendizagem informal à aprendizagem formal. Porto: Edições Asa, 2002.

VIGOTSKY, L. S., A formação sócial da mente. São Paulo: Martins Fontes, 1984.

YIN, R. K. Estudo de caso. Porto Alegre: Artmed, 2001.

ZIMMER, J.; PICONEZ, S.; AMANTE, L. Uso de blog: contribuições para formação docente e educação escolar" In L. M. Fadel; V. R. Ulbricht e M. C. Neto (Orgs). Hipermídia e acessibilidade na era da inclusão. Ideia Editora. João Pessoa, Brasil, p. 295-348, 2013. http://conahpa. sites.ufsc.br/wp-content/uploads/2013/09/acessibilidade_conahpa_pc.pdf

Enviado em: 17 de julho de 2019

Apreciado em: 20 de julho de 2019

Inserido em: 01 de agosto de 2019 